\title{
Nitrate Adsorption on Clay Kaolin: Batch Tests
}

\author{
Morteza Mohsenipour, ${ }^{1}$ Shamsuddin Shahid, ${ }^{1}$ and Kumars Ebrahimi ${ }^{2}$ \\ ${ }^{1}$ Department of Hydraulics and Hydrology, Faculty of Civil Engineering, Universiti Teknologi Malaysia (UTM), \\ 81310 Johor Bahru, Malaysia \\ ${ }^{2}$ Irrigation and Reclamation Engineering Department, University of Tehran, Karaj 77871-31587, Iran
}

Correspondence should be addressed to Morteza Mohsenipour; mmorteza2@live.utm.my

Received 4 December 2014; Revised 12 March 2015; Accepted 13 March 2015

Academic Editor: Kaustubha Mohanty

Copyright (C) 2015 Morteza Mohsenipour et al. This is an open access article distributed under the Creative Commons Attribution License, which permits unrestricted use, distribution, and reproduction in any medium, provided the original work is properly cited.

\begin{abstract}
Soils possessing kaolin, gibbsite, goethite, and hematite particles have been found to have a natural capacity to attenuate pollution in aqueous phase. On the other hand, the hydroxyl group in soil increases anion exchange capacity under a low $\mathrm{pH}$ condition. The main objective of this paper was to evaluate effects of kaolin on nitrate reduction under acidic condition. In order to analyze the kaolin adsorption behaviour under various conditions, four different concentrations of nitrate, 45, 112.5, 225, and $450 \mathrm{mgNO}_{3}{ }^{-} / \mathrm{L}$, with a constant $\mathrm{pH}$ equal to 2 , constant temperature equal to $25^{\circ} \mathrm{C}$, and exposure period varying from 0 to 150 minutes were considered. The capacity of nitrate adsorption on kaolin has also been studied involving two well-known adsorption isotherm models, namely, Freundlich and Longmuir. The results revealed that approximately $25 \%$ of the nitrate present in the solution was adsorbed on clay kaolin. The laboratory experimental data revealed that Freundlich adsorption isotherm model was more accurate than Longmuir adsorption model in predicting of nitrate adsorption. Furthermore, the retardation factor of nitrate pollution in saturated zone has been found to be approximately 4 in presence of kaolin, which indicated that kaolin can be used for natural scavenger of pollution in the environment.
\end{abstract}

\section{Introduction}

Groundwater and soil can be polluted through various anthropogenic activities such as pesticide use and industrial processes [1]. The breaking of the ecological equilibrium between human being and the nature is the main reason of environmental contamination issue [2]. Since 1970s nitrate leaching to subsoil has become an important environmental quality and human health issue, especially due to high use of nitrogen as nutrient in agriculture [3-5]. Inorganic nitrogen is used as an essential fertilizer in intensive agriculture to produce sufficient food for growing population and food security, a substantial part of which finally infiltrates into subsurface and contaminates soil and groundwater [6-8]. Nitrate itself is relatively nontoxic, but nitrite derived by the reduction of nitrate, which can cause various human health problems such as methemoglobinemia, liver damage, and even cancers [9]. Although nitrate is highly soluble in water $[10]$ and does not readily bind to the soil and leaches due to massive irrigation and heavy rains [11], the movement of some anions like nitrate is retarded by variable surfacecharge of soil particles [12-15]. Various soil and solution parameters which have an effect on nitrate concentration in porous medium are categorized as follows: ionic strength [16], aluminum oxide concentrations [17], competition with other anions [18], $\mathrm{pH}$ of soil solutions [19], soil texture and clay mineralogy [20], and organic matter content [21].

Townsend and Young [22]; Pociene and Pocius [23]; Gurdak and Qi [24]; O'Reilly et al. [25]; and a number of other researchers have reported statistical relationship between nitrate pollution and soil as well as the solution properties. According to Townsend and Young [22], the thickness of clay above the well screen has positive effect on the reduction of nitrate in groundwater. Pociene and Pocius [23] reported that (i) the amount of nitrate in clayey soil is more than sandy soil; (ii) clay and humus have impact on the leaching and concentration of nitrogen into groundwater; and (iii) relationship between the amount of clay particles and nitrogen leaching is inverse. Vulnerability of groundwater to nitrate in shallow depth tube-wells with less clay or organic 
TABLE 1: Chemical composition of kaolin used in the current study.

\begin{tabular}{lc}
\hline Parameter & Result (\%) \\
\hline Silica as $\mathrm{SiO}_{2}$ & 45.72 \\
Aluminum as $\mathrm{Al}_{2} \mathrm{O}_{3}$ & 37.54 \\
Titanium as $\mathrm{TiO}_{2}$ & 1.10 \\
Iron as $\mathrm{Fe}_{2} \mathrm{O}_{3}$ & 0.86 \\
Sodium as $\mathrm{Na}_{2} \mathrm{O}$ & 0.02 \\
Potassium as $\mathrm{K}_{2} \mathrm{O}$ & 1.29 \\
Calcium as $\mathrm{CaO}$ & $<0.01$ \\
Magnesium as $\mathrm{MgO}$ & 0.51 \\
Loss on ignition at $1025^{\circ} \mathrm{C}$ & 13.0 \\
\hline
\end{tabular}

matter in unsaturated zone above the groundwater table has been reported greater than other areas [24]. O'Reilly et al. [25] remarked that clay particles in saturated porous media may retard the transport of groundwater pollution. Therefore, purification of water using low cost natural and modified adsorbents such as clay minerals can be a cost-effective and sustainable approach [26].

Different soils, including kaolin, gibbsite, goethite, and hematite particles, have potential to retard nitrate contamination transport to groundwater. The hydroxyl group in these soils increases anion exchange capacity (AEC) under acidic conditions, which causes retardation of nitrate movement $[8$, 13-15, 27]. Based on the literature review, it can be remarked that though many efforts have been taken to investigate the behaviour of nitrate movement in different soils, the knowledge on the effect of kaolin on nitrate retention at low $\mathrm{pH}$ is still unknown. The objectives of the present study are (1) to assess nitrate adsorption by clay kaolin under acidic condition; (2) to find adsorption isotherm model to evaluate the adsorption capacity of kaolin; and (3) to predict retardation factor of nitrate movement in porous media in the presence of clay kaolin. It is expected that the present study will help to improve knowledge on nitrate movement in clay under acidic condition which in turn will help to prevent groundwater contamination and keep nitrate in root zone for plant uptake.

\section{Materials and Methods}

2.1. Soil Sample. Kaolin is one of the most common minerals in various countries around the world. Kaolin clay originates from the chemical weathering of rocks in hot and moist climates and is usually abundant in soils. For the present study, the kaolin extracted from the state of Perak, Malaysia, was collected from Kaolin Company (Malaysia). The chemical properties of kaolin used in the present study are given in Table 1.

2.2. Chemical Used. According to the World Health Organization (WHO) guidelines, the maximum limit of nitrate in drinking water is $45 \mathrm{mgNO}_{3}{ }^{-} / \mathrm{L}$; excessive nitrate $(>45 \mathrm{mg} / \mathrm{L})$ in the drinking water causes health risks [28]. Studies around the world indicate that nitrate concentration in groundwater in most parts of the world has not increased more than ten times of the maximum nitrate limit prescribed by WHO. Therefore, the range of nitrate concentration for laboratory tests was chosen from 45 up to $450 \mathrm{mgNO}_{3}{ }^{-} / \mathrm{L}$. Stock solution of nitrate at concentration of $1000 \mathrm{mgN} / \mathrm{L}$ was prepared by dissolving $7.218 \mathrm{~g}$ of potassium nitrate $\left(\mathrm{KNO}_{3}\right)$ of analytical reagent (QReC) in one liter of distilled water. The test solutions with nitrate at concentrations, 45, 112.5, 225, and $450 \mathrm{mgNO}_{3}{ }^{-} / \mathrm{L}$, were prepared by diluting stock nitrate solution to the desired concentrations.

2.3. Adsorption Study. Adsorption tests were conducted at laboratory room temperature $\left(\sim 25^{\circ} \mathrm{C}\right)$. A $2 \mathrm{~g}$ of kaolin (measured by digital balance scale model-SHIMADZO, UX $1020 \mathrm{H}$ ) and $20 \mathrm{~mL}$ nitrate solution were contacted in 200$\mathrm{mL}$ Erlenmeyer flask for this purpose. Initial nitrate concentration was $45,112.5,225$, and $450 \mathrm{mgNO}_{3}{ }^{-} / \mathrm{L}$. The $\mathrm{pH}$ of solution was adjusted by using concentrated hydrochloric acid, HCL 37\%, (QReC) and was kept constant at 2 for all adsorption tests (Milwuakee-pH600). Rotary shaker (WiseShake-SHR-2D) was used to shake samples at $120 \mathrm{rpm}$. The contact time between adsorbent and solution was ranged from $15 \mathrm{~min}$ to $2.5 \mathrm{hr}$. Different conditions like contact time and initial concentration were also tested. After desire time, water sampling was conducted and solution was separated from the adsorbent using filter paper (Ashless filter 203). All samples were prepared using brucine sulfanilic acid reagent method in order to measure nitrate concentration. Brucine sulfanilic acid changed the color of the samples to different shades of yellow (from light to deep yellow) depending on the concentration of nitrate in the sample. The final concentration of nitrate in solution was determined by measuring the absorbance at $410 \mathrm{~nm}$ by UV-VIS spectrophotometer (BIOTEK, ELx 808). All experiments were performed in duplicate and the average values were used for calculation.

2.4. Estimation of the Amount of Adsorption. The percentage and the amount of nitrate adsorption at equilibrium concentration on absorbent surface were calculated as

$$
\begin{gathered}
\text { Percent of adsorption }=\frac{\left(C_{i}-C_{e}\right)}{C_{i}} \\
q_{e}=\left(C_{i}-C_{e}\right) \frac{V}{X}
\end{gathered}
$$

where $q_{e}$ is the amount of the solute adsorbed per mass unit of adsorbent $(\mathrm{mg} / \mathrm{g}), C_{i}$ is the initial concentration in the aqueous phase $(\mathrm{mg} / \mathrm{L}), C_{e}$ is the concentration in the aqueous phase at equilibrium $(\mathrm{mg} / \mathrm{L}), V$ is the volume of the aqueous phase (L), and $X$ is the weight of the absorbent $(\mathrm{g})$.

2.5. Estimation of Adsorption Isotherm. An adsorption isotherm is a curve which shows the relationship between equilibrium concentration and the amount of solute on the adsorbent in the aqueous phase. In order to evaluate the nitrate adsorption capacity of kaolin, the equilibrium adsorption of nitrate was studied as a function of nitrate concentration and the adsorption isotherms. There are several models for predicting the equilibrium distribution. However, 


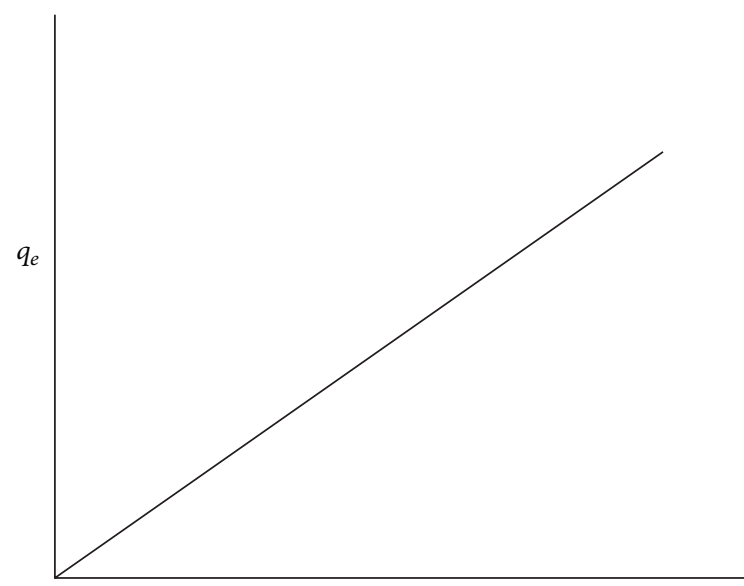

$\mathrm{C}_{e}$

(a) linear

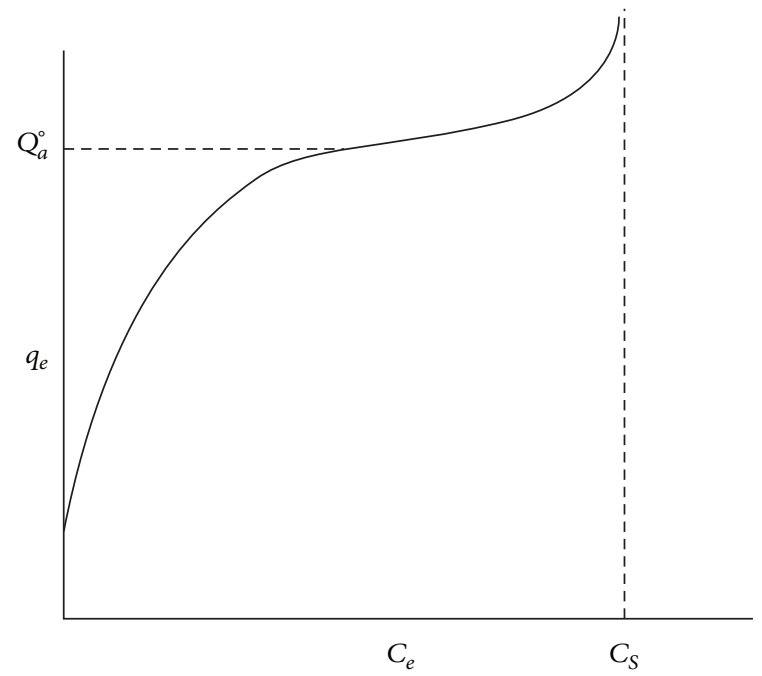

(c) BET

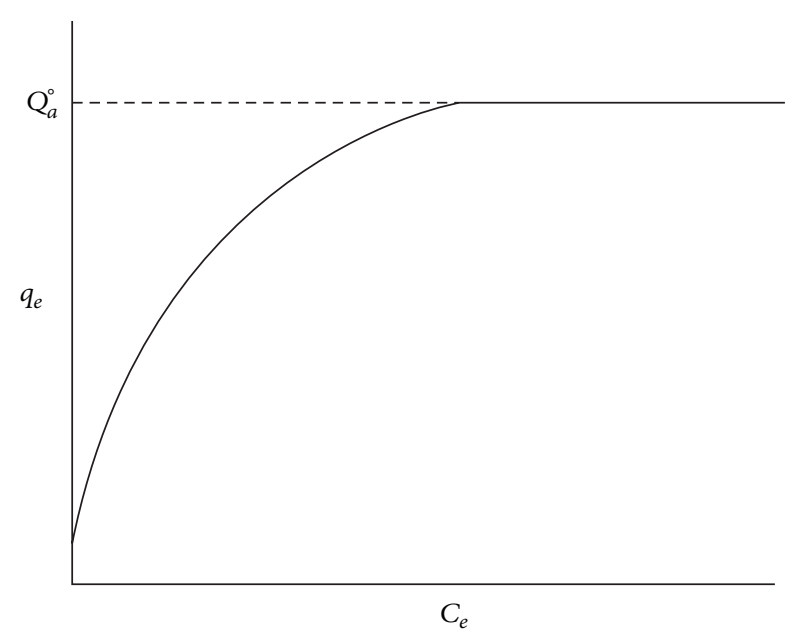

(b) Langmuir

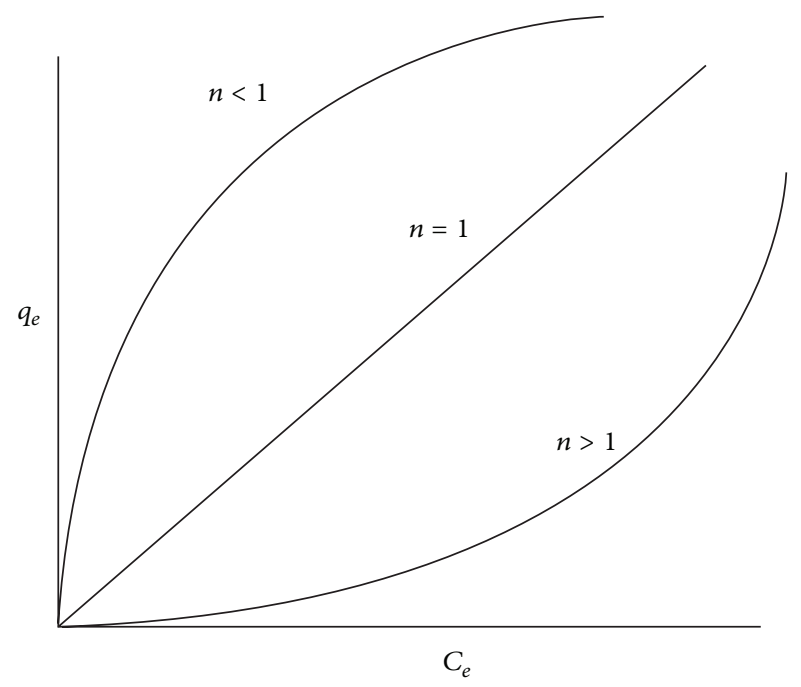

(d) Freundlich

FIGURE 1: Different models of adsorption isotherm (a) linear; (b) Langmuir; (c) BET; and (d) Freundlich.

the linear, Freundlich, Langmuir, and Brunauer-EmmettTeller (BET) are the most commonly used models, which are shown in Figure 1.

A number of researchers $[7,8,29-31]$ reported that two nonlinear adsorption isotherms, namely, Langmuir and Freundlich, are the best models to explain the trend of adsorption based on the essence of absorbents saturated with adsorbate after enough contact time.

Freundlich isotherm is an empirical equation. The nonlinear form of Freundlich's equation is written as [32]

$$
q_{e}=K_{f} C_{e}^{1 / n}
$$

where $q_{e}$ is the amount of the solute adsorbed per mass unit of adsorbent $(\mathrm{mg} / \mathrm{g}), C_{e}$ is the equilibrium aqueous pollutant concentration $(\mathrm{mg} / \mathrm{L}), K_{f}$ is Freundlich constant, and $n$ is Freundlich exponent, $K_{f}$ is the indicator of adsorption capacity, and $1 / n$ is a measure of intensity of adsorption.
Freundlich is an exponential equation which can be used to determine the values of parameters. The logarithm conversion is one way to determine Freundlich parameters. Therefore (3) converts to

$$
\log q_{e}=\log K_{f}+\frac{1}{n} \log C_{e} .
$$

By plotting $\log q_{e}$ against $\log C_{e}$, the values of Freundlich parameters can be determined. The slope of line is the exponent and the logarithm of intercept is the constant of Freundlich parameters.

Langmuir adsorption isotherm is given as

$$
q_{e}=\frac{q_{\max \times C_{e} \times K}}{1+C_{e} \times K},
$$

where $q_{e}$ is the amount of the solute adsorbed per mass unit of adsorbent $(\mathrm{mg} / \mathrm{g}) ; C_{e}$ is the equilibrium concentration of the aqueous phase $(\mathrm{mg} / \mathrm{L})$; and $q_{\max }$ is the maximum 
TABLE 2: Nitrate adsorption for different initial concentration.

\begin{tabular}{lccc}
\hline$C_{0}\left(\mathrm{mgNO}_{3}{ }^{-} / \mathrm{L}\right)$ & $C_{e}\left(\mathrm{mgNO}_{3}{ }^{-} / \mathrm{L}\right)$ & $q_{e}(\mathrm{mg} / \mathrm{g})$ & $\begin{array}{c}\text { Percent of } \\
\text { adsorption } \\
(\%)\end{array}$ \\
\hline 45 & 35 & 0.10 & 22.2 \\
112.5 & 84 & 0.28 & 25.3 \\
225 & 165 & 0.60 & 26.7 \\
450 & 326 & 1.24 & 27.5 \\
\hline
\end{tabular}

amount adsorbed. The parameters, $q_{\max }$ and $K$, are Langmuir constants.

2.6. Calculation of Retardation Factor. Retardation factor is a dimensionless parameter in the governing equation of solute transport in porous media. It is defined as the relative ratio of water velocity to solute velocity [33]. Consider

$$
R_{d}=1+\frac{\rho_{b} K_{d}}{n},
$$

where $R_{d}$ is the retardation factor (dimensionless), $\rho_{b}$ is the bulk density of soil sample $\left(\mathrm{g} / \mathrm{cm}^{3}\right), K_{d}$ is the adsorption or distribution coefficient $\left(\mathrm{cm}^{3} / \mathrm{g}\right)$, and $n$ is the porosity $\left(\mathrm{cm}^{3} / \mathrm{cm}^{3}\right)$.

The adsorption or distribution coefficient $K_{d}$ can be estimated as

$$
K_{d}=\frac{q_{e}}{C_{e}} .
$$

\section{Results and Discussion}

3.1. Effect of Initial Concentration. The effect of initial nitrate concentration on equilibrium adsorption was investigated at different initial nitrate concentrations. Four different initial concentrations, mentioned in Section 2.2, were used to assess the capability of kaolin on nitrate adsorption. The percentage and the amount of nitrate adsorption at equilibrium concentration for all initial concentrations were calculated using (1) and (2), which are shown in Table 2.

Table 2 revealed that initial nitrate concentration has an effect on the amount of nitrate adsorption at equilibrium. The equilibrium adsorption values increased from $0.1 \mathrm{mg} / \mathrm{g}$ to $1.24 \mathrm{mg} / \mathrm{g}$ with an increase of initial concentration from 45 to $450 \mathrm{mgNO}_{3}{ }^{-} / \mathrm{L}$, respectively. However, the increasing rate of nitrate adsorption decelerated with further increase in nitrate concentration. This behavior is due to the increase in the driving force of the concentration gradient, as further increase in the initial nitrate concentration overcomes the limitations of low adsorption by absorbent [7]. Such phenomenon is common in a batch test with either constant adsorbent dose or varying initial adsorbate concentration or vice versa [34]. Therefore, it can be remarked that nitrate adsorption process at higher initial concentration is enhanced compared to the case at lower initial nitrate concentration. Percentages of nitrate adsorption at different initial nitrate concentrations are shown in Figure 2. The percentages of nitrate adsorption

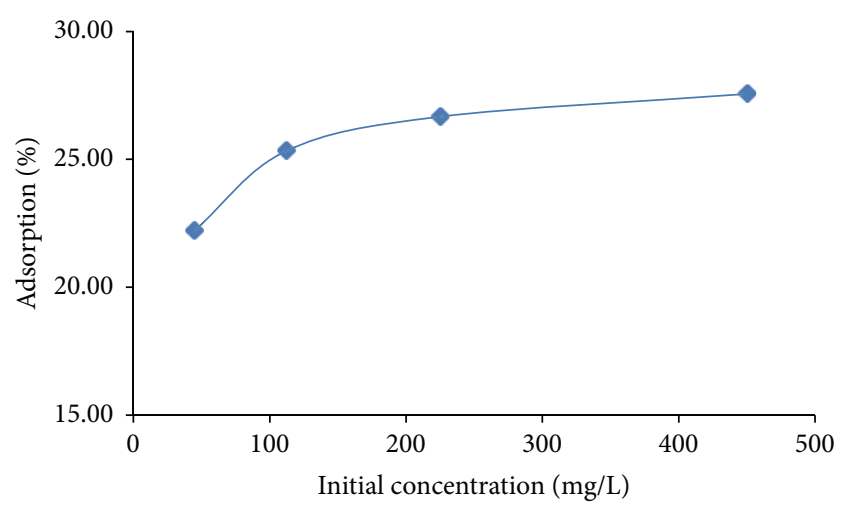

FIGURE 2: Percentage of nitrate adsorption (\%) in aqueous phase, at $T=25^{\circ} \mathrm{C}, \mathrm{pH}=2, v=20 \mathrm{~mL}, X=2 \mathrm{~g}$, and different $C_{0}$.

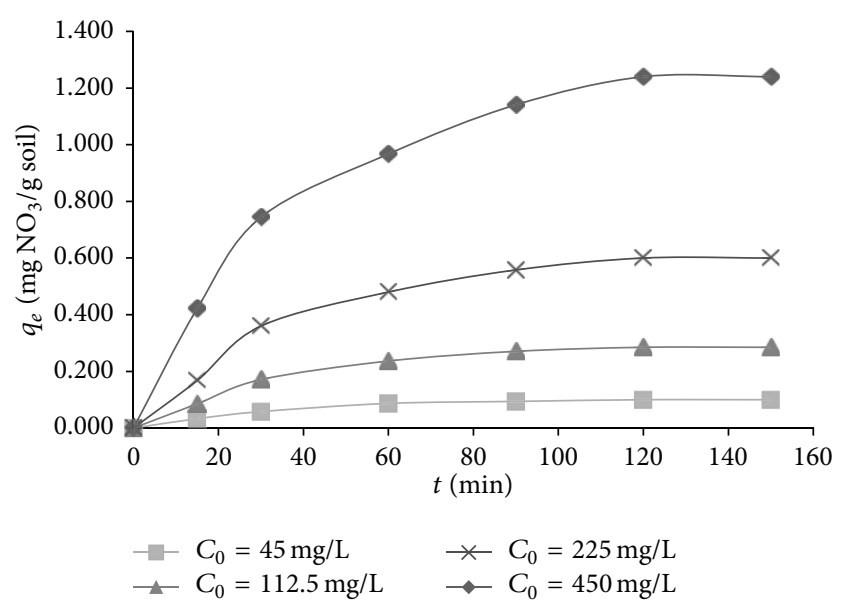

FIGURE 3: Effect of contact time on nitrate adsorption by clay kaolin in samples, at $T=25^{\circ} \mathrm{C}, \mathrm{pH}=2, v=20 \mathrm{~mL}, X=2 \mathrm{~g}$, and different $C_{0}$.

in aqueous phase were approximately $22.2 \%$ and $27.5 \%$ for the lowest and highest initial nitrate concentrations, respectively. Figure 2 shows that the slope of curve in lower nitrate concentrations was steeper than at higher nitrate concentrations. Constant adsorbent, $2 \mathrm{~g}$, for all tests and much availability of nitrate anion at higher concentrations have caused flattening of the slope of the curve.

3.2. Effect of Contact Time on Nitrate Adsorption. Water sampling was conducted at different times from the start of experimental test as mentioned in Section 2.3 to measure the nitrate adsorption by adsorbent at any nitrate concentration. Equation (2) was used to calculate the amount of nitrate adsorption at a particular time of water sampling. The amount of adsorptions, $q_{e}$, versus related times was depicted for different nitrate concentrations and present in Figure 3. The figure represents the effect of contact time on nitrate adsorption for various samples.

The rate of nitrate adsorption (Figure 3 ) can be divided into two parts; one represents rapid nitrate adsorption and 


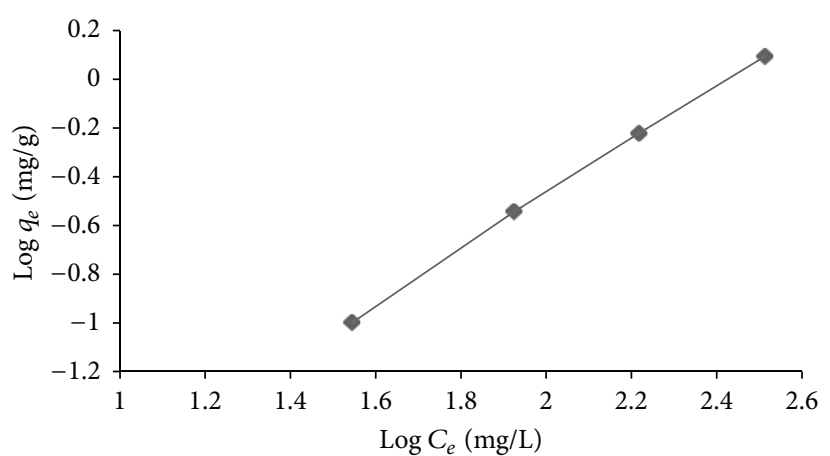

(a)

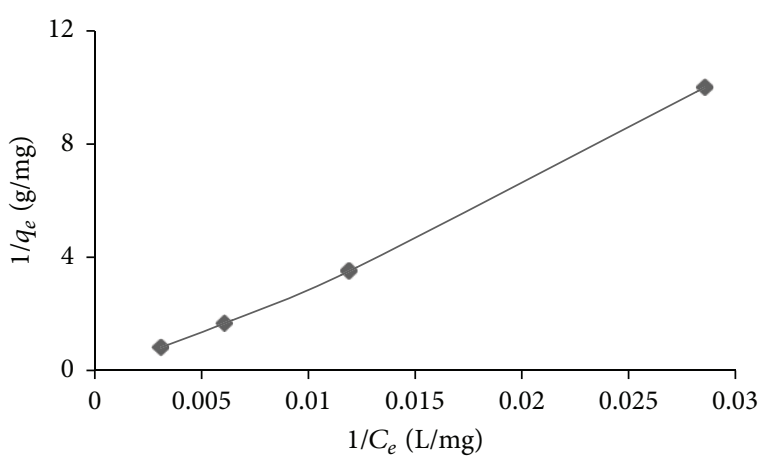

(b)

FIgURE 4: (a) Linearized Freundlich; (b) Langmuir adsorption isotherm on experimental data, at $T=25^{\circ} \mathrm{C}, \mathrm{pH}=2, v=20 \mathrm{~mL}, X=2 \mathrm{~g}$, and different $C_{0}$.

another represents slow nitrate adsorption. Duration time for rapid nitrate adsorption was approximately 50 minutes. During this period, the tendency of absorbent to adsorption was high and therefore, the slope of adsorption curve was steep. Slow adsorption rate was between 50 and 120 minutes. During this period, the slope of adsorption curve was gradually flattened, and the nitrate adsorption was gradually decreased until reaching zero. This usually occurs as the external surface of kaolin is rapidly saturated by nitrate anion and therefore the adsorption rate reduces [7]. Approximately, 120 minutes was taken for nitrate adsorption into kaolin and reaching equilibrium in the experiment.

3.3. Adsorption Isotherm. Based on the method mentioned in Section 2.5 and using the data given in Table 2, the plots of $\log q_{e}$ versus $\log C_{e}$, and $1 / q_{e}$ versus $1 / C_{e}$ were depicted to show the Freundlich and Langmuir isotherms, respectively, in order to find the best model of adsorption isotherm that can describe experimental data (Figure 4). The results showed that Freundlich adsorption isotherm had better matching on data with $R^{2}=0.99$ than Langmuir adsorption isotherm with $R^{2}=0.97$. Linearized Freundlich adsorption isotherm was used to calculate $K_{f}$ and $n$ which is shown in Figure 4(a). The parameters of Freundlich's equation obtained from Figure 4(a) were 0.0018 and 0.887 for $K_{f}$ and $n$, respectively. Freundlich equation based on mentioned conditions and criteria to calculate nitrate adsorption capacity was obtained as

$$
q_{e}=0.0018 C_{e}^{0.887}
$$

The value of $1 / n$ in the current study was 1.127 . The intensity of adsorption, $1 / n=1$, means reaction between solute and adsorbent is linear; $1 / n<1$ means the shape of nonlinear adsorption isotherm is convex and adsorption is unfavorable at lower equilibrium concentration; and $1 / n>1$ means the shape of nonlinear adsorption isotherm is concave and the adsorption is more favorable at lower equilibrium concentration. Therefore, the value of $1 / n, 1.127$, indicates that adsorption of nitrate by kaolin particles was dominated in aqueous phase.
3.4. Retardation Factor. A physical scale model was constructed in the Hydraulics Laboratory at Faculty of Civil Engineering, Universiti Teknologi Malaysia, for laboratory experiment. Experimental tests were conducted using the above mentioned laboratory model with a constant seepage velocity rate and initial nitrate concentration. The values of seepage rate and initial nitrate concentration were kept constant at $v=0.0047 \mathrm{~cm} / \mathrm{s}, C_{0}=112.5 \mathrm{mgNO}_{3}{ }^{-} / \mathrm{L}$, respectively. Mixed sand (85\%) and kaolin (15\%) were used as porous medium. The porosity, bulk density $\left(\rho_{b}\right)$, hydraulic conductivity, and longitudinal dispersion coefficient values of the media were obtained through laboratory soil column experiments. The results showed that the porosity of the media was $0.41 \mathrm{~cm}^{3} / \mathrm{cm}^{3}$, bulk density was $1.5 \mathrm{~g} / \mathrm{cm}^{3}$, hydraulic conductivity was $0.0153 \mathrm{~cm} / \mathrm{s}$, and longitudinal dispersion coefficient was $0.0037 \mathrm{~cm}^{2} / \mathrm{s}$. The value of absorption or distribution coefficient $\left(K_{d}\right)$ was calculated as $0.918 \mathrm{~cm}^{3} / \mathrm{g}$ using (7). Finally, substituted laboratory data in (6) showed that the retardation factor was approximately 4 . The result showed that kaolin under experimental condition can retain nitrate in soil. Therefore, it can be remarked that kaolin can play a significant role in nitrate adsorption to prevent leaching in groundwater.

\section{Conclusion}

Batch experimental tests on nitrate adsorption showed that kaolin particles are capable of adsorbing nitrate pollution and retaining it in soils. The mean percentage of nitrate reduction in solution was $25 \%$ for initial concentration. Nitrate contamination was retarded in porous medium by kaolin particles. The retardation factor was calculated approximately 4 under acidic condition. It can be concluded from this study that existing kaolin particles in soil can retain and attenuate nitrate pollution to prevent groundwater contamination which in turn can help to achieve sustainability in groundwater use. Finally, it can be remarked that easy availability of various types of clay kaolin and their ability to adsorb and retain nitrate $[34,35]$ will create more interest to develop new natural adsorption method of pollutant removal from solution. 


\section{Conflict of Interests}

The authors declare that there is no conflict of interests regarding the publication of this paper.

\section{Acknowledgments}

The authors are grateful to the Ministry of Education Malaysia and Universiti Teknologi Malaysia (UTM) for supporting this research through FRGS Grant no. R. J. 130000.7822.4F541. Also the first author acknowledges Water Research Alliance, Universiti Teknologi Malaysia, for sponsoring the attendance of a publication workshop which helped to improve the quality of the paper.

\section{References}

[1] K. K. Deshmukh, "Impact of human activities on the quality of groundwater from Sangamner Area, Ahmednagar District, Maharashtra, India," International Research Journal of Environment Sciences, vol. 2, no. 8, pp. 66-74, 2013.

[2] V. Vasilache, C. Filote, M. A. Cretu et al., "Monitoring of groundwater quality in some vulnerable areas in botosani county for nitrates and nitrites based pollutants," Environmental Engineering and Management Journal, vol. 11, no. 2, pp. 471-479, 2012.

[3] M. Tani, T. Okuten, M. Koike, K. Kuramochi, and R. Kondo, "Nitrate adsorption in some andisols developed under different moisture conditions," Soil Science and Plant Nutrition, vol. 50, no. 3, pp. 439-446, 2004.

[4] A. M. González-Delgado and M. K. Shukla, "Coupled transport of nitrate and chloride in soil columns," Soil Science, vol. 176, no. 7, pp. 346-355, 2011.

[5] N. A. Qambrani, S. H. Jung, Y. S. Ok, Y. S. Kim, and S.-E. Oh, "Nitrate-contaminated groundwater remediation by combined autotrophic and heterotrophic denitrification for sulfate and $\mathrm{pH}$ control: batch tests," Environmental Science and Pollution Research, vol. 20, no. 12, pp. 9084-9091, 2013.

[6] N. M. Crawford and A. D. M. Glass, "Molecular and physiological aspects of nitrate uptake in plants," Trends in Plant Science, vol. 3, no. 10, pp. 389-395, 1998.

[7] W. Hamdi, F. Gamaoun, D. E. Pelster, and M. Seffen, "Nitrate sorption in an agricultural soil profile," Applied and Environmental Soil Science, vol. 2013, Article ID 597824, 7 pages, 2013.

[8] N. P. Qafoku, M. E. Sumner, and D. E. Radcliffe, "Anion transport in columns of variable charge subsoils: nitrate and chloride," Journal of Environmental Quality, vol. 29, no. 2, pp. 484-493, 2000.

[9] C.-P. Huang, H.-W. Wang, and P.-C. Chiu, "Nitrate reduction by metallic iron," Water Research, vol. 32, no. 8, pp. 2257-2264, 1998.

[10] T. S. Thompson, "Nitrate concentrations in private rural drinking water supplies in Saskatchewan, Canada," Bulletin of Environmental Contamination and Toxicology, vol. 66, no. 1, pp. 64-70, 2001.

[11] A. Bhatnagar and M. Sillanpää, "A review of emerging adsorbents for nitrate removal from water," Chemical Engineering Journal, vol. 168, no. 2, pp. 493-504, 2011.

[12] H. Katou, B. E. Clothier, and S. R. Green, "Anion transport involving competitive adsorption during transient water flow in an andisol," Soil Science Society of America Journal, vol. 60, no. 5, pp. 1368-1375, 1996.

[13] G. Bellini, M. E. Sumner, D. E. Radcliffe, and N. P. Qafoku, "Anion transport through columns of highly weathered acid soil: adsorption and retardation," Soil Science Society of America Journal, vol. 60, no. 1, pp. 132-137, 1996.

[14] G. P. Warren and F. M. Kihanda, "Nitrate leaching and adsorption in a Kenyan Nitisol," Soil Use and Management, vol. 17, no. 4, pp. 222-228, 2001.

[15] C. Duwig, T. Becquer, L. Charlet, and B. E. Clothier, "Estimation of nitrate retention in a Ferralsol by a transient-flow method," European Journal of Soil Science, vol. 54, no. 3, pp. 505-515, 2003.

[16] G. Sposito, The Chemistry of Soils, Oxford University Press, Oxford, UK, 2008.

[17] M. T. F. Wong and K. Wittwer, "Positive charge discovered across Western Australian wheatbelt soils challenges key soil and nitrogen management assumptions," Australian Journal of Soil Research, vol. 47, no. 1, pp. 127-135, 2009.

[18] F. Feder and A. Findeling, "Retention and leaching of nitrate and chloride in an andic soil after pig manure amendment," European Journal of Soil Science, vol. 58, no. 2, pp. 393-404, 2007.

[19] M. J. Donn and N. W. Menzies, "Simulated rainwater effects on anion exchange capacity and nitrate retention in Ferrosols," Australian Journal of Soil Research, vol. 43, no. 1, pp. 33-42, 2005.

[20] N. Martínez-Villegas, L. M. Flores-Vélez, and O. Domínguez, "Sorption of lead in soil as a function of $\mathrm{pH}$ : a study case in México," Chemosphere, vol. 57, no. 10, pp. 1537-1542, 2004.

[21] M. R. Panuccio, A. Muscolo, and S. Nardi, "Effect of humic substances on nitrogen uptake and assimilation in two species of pinus," Journal of Plant Nutrition, vol. 24, no. 4-5, pp. 693704, 2001.

[22] M. A. Townsend and D. P. Young, "Factors affecting nitrate concentrations in ground water in Stafford County, Kansas," Current Research on Kansas Geology, vol. 238, pp. 1-9, 1995.

[23] A. Pociene and S. Pocius, "Relationship between nitrate amount in groundwater and natural factors," Journal of Environmental Engineering and Landscape Management, vol. 13, no. 1, pp. 2330, 2005.

[24] J. J. Gurdak and S. L. Qi, "Vulnerability of recently recharged groundwater in the high plains aquifer to nitrate contamination," Report 2006-5050, U.S. Geological Survey Scientific Investigations, 2006.

[25] A. M. O’Reilly, N. B. Chang, and M. P. Wanielista, "Data mining analysis of nitrate occurrence in ground water in Central and Northeast Florida and an overview of stormwater best management practices for nitrate control," in Proceedings of the 9th Biennial Stormwater Research and Watershed Management Conference, pp. 2-3, Orlando, Fla, USA, 2007.

[26] R. Srinivasan, "Advances in application of natural clay and its composites in removal of biological, organic, and inorganic contaminants from drinking water," Advances in Materials Science and Engineering, vol. 2011, Article ID 872531, 17 pages, 2011.

[27] F. K. Nakagawa, G. B. S. Forti, M. E. Alves, A. Lavorenti, and J. H. de Miranda, "Estimating subsoil resistance to nitrate leaching from easily measurable pedological properties," Revista Brasileira de Ciência do Solo, vol. 36, no. 5, pp. 1491-1498, 2012.

[28] Archna, S. K. Sharma, and R. C. Sobti, "Nitrate removal from ground water: a review," E-Journal of Chemistry, vol. 9, no. 4, pp. 1667-1675, 2012. 
[29] A. Bhatnagar, E. Kumar, and M. Sillanpää, "Nitrate removal from water by nano-alumina: characterization and sorption studies," Chemical Engineering Journal, vol. 163, no. 3, pp. 317323,2010

[30] J. Mikołajków, "Laboratory methods of estimating the retardation factor of migrating mineral nitrogen compounds in shallow groundwater," Geological Quarterly, vol. 47, no. 1, pp. 91-96, 2003.

[31] J. Hizal and R. Apak, "Modeling of cadmium(II) adsorption on kaolinite-based clays in the absence and presence of humic acid," Applied Clay Science, vol. 32, no. 3-4, pp. 232-244, 2006.

[32] C. Zheng and G. D. Bennett, Applied Contaminant Transport Modeling, John Wiley \& Sons, New York, NY, USA, 2nd edition, 2002.

[33] R. A. Freeze and J. A. Herry, Groundwater, Prentice-Hall, Englewood Cliffs, NJ, USA, 1979.

[34] K. H. Chu, "Removal of copper from aqueous solution by chitosan in prawn shell: adsorption equilibrium and kinetics," Journal of Hazardous Materials, vol. 90, no. 1, pp. 77-95, 2002.

[35] V. K. Gupta, I. Ali, and V. K. Saini, "Defluoridation of wastewaters using waste carbon slurry," Water Research, vol. 41, no. 15, pp. 3307-3316, 2007. 

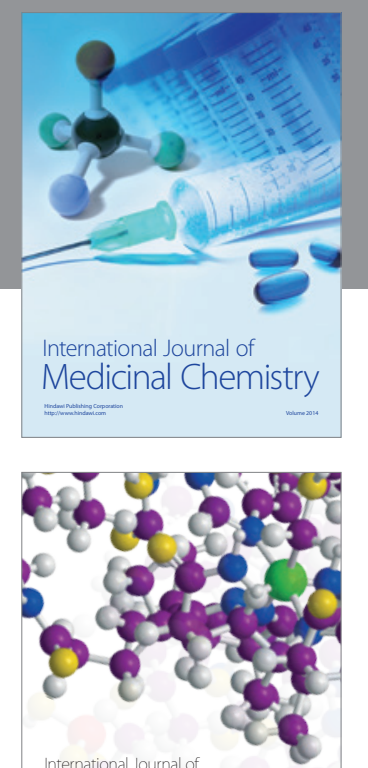

\section{Carbohydrate} Chemistry

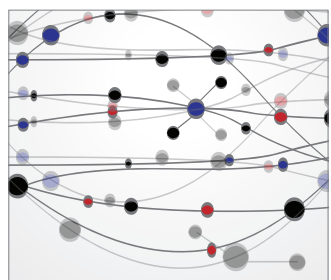

The Scientific World Journal
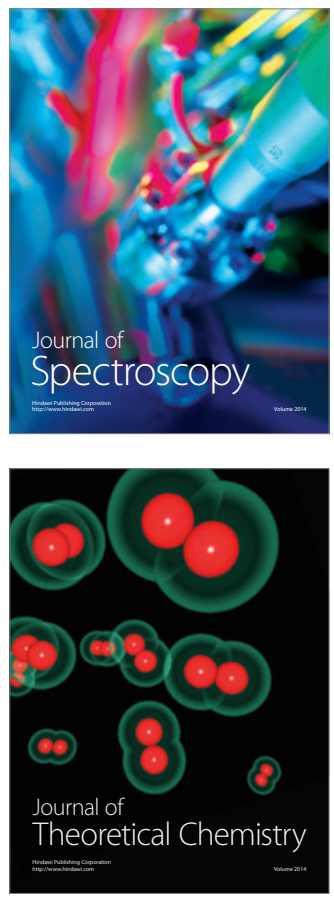
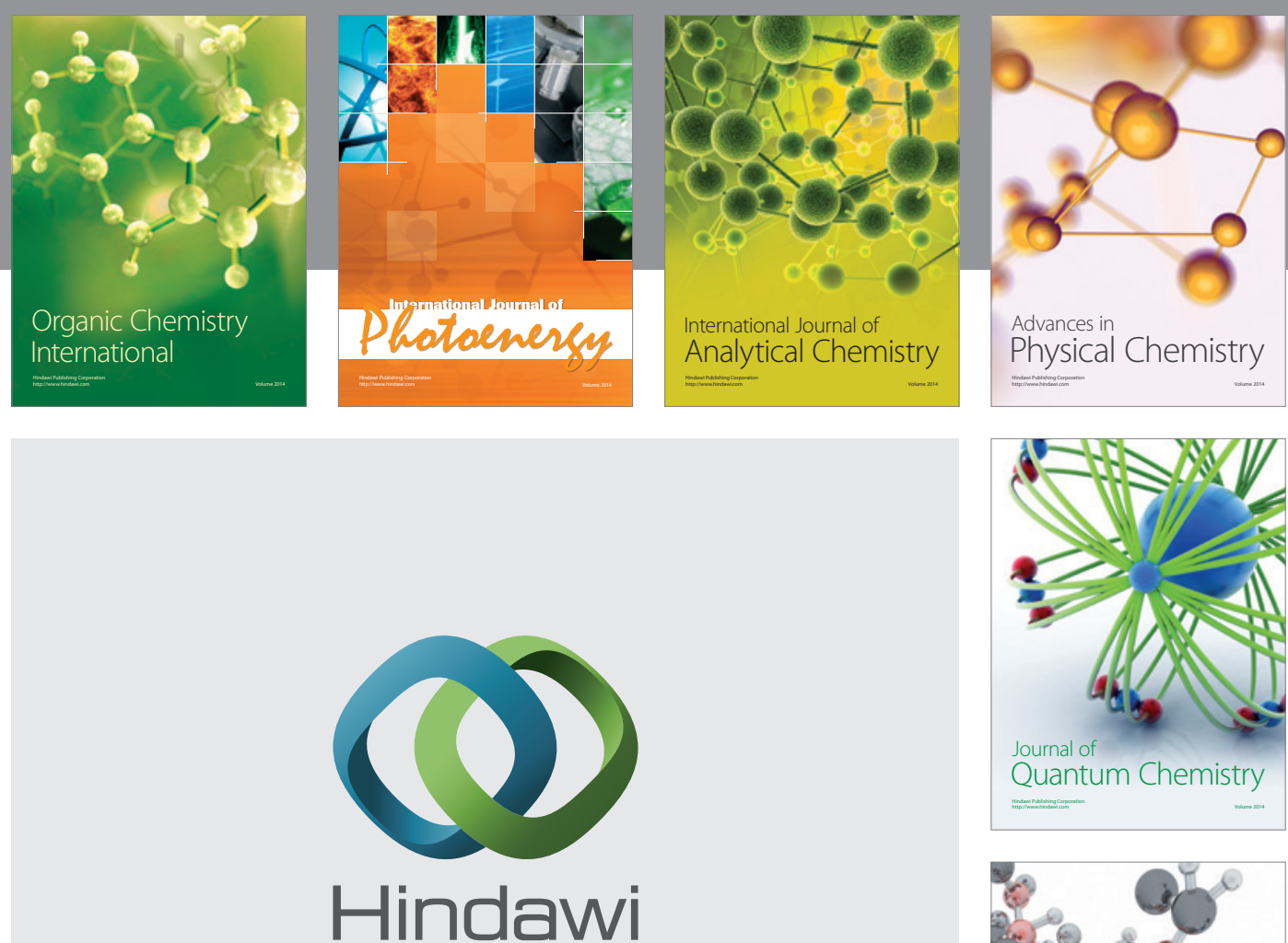

Submit your manuscripts at

http://www.hindawi.com

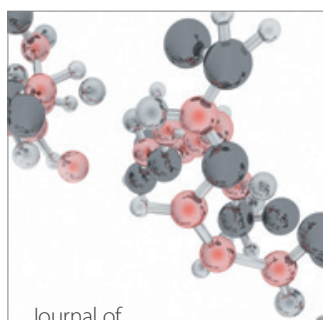

Analytical Methods

in Chemistry

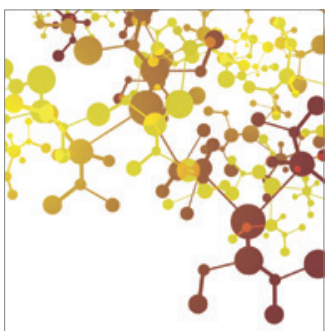

Journal of

Applied Chemistry

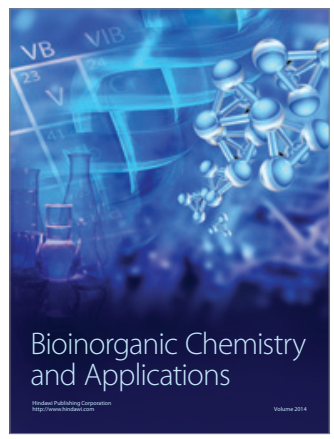

Inorganic Chemistry
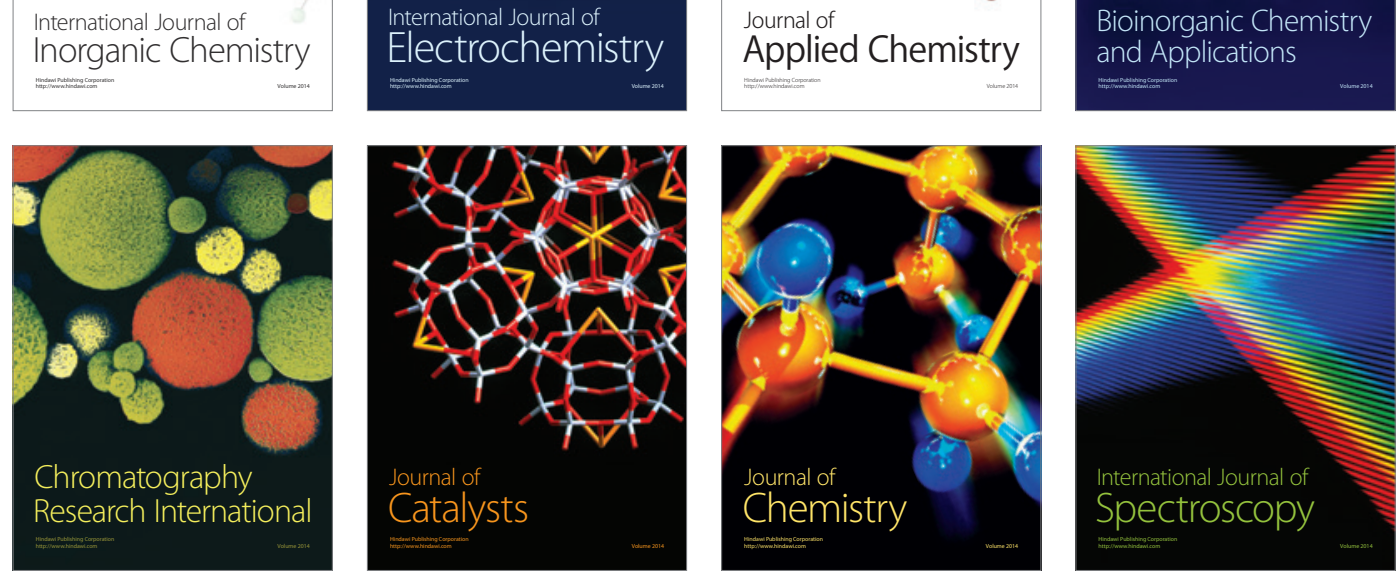